\title{
Un análisis filosófico de la Bibliotecología
}

\author{
Miguel Ángel Rendón Rojas \\ Investigador del Centro Universitario de \\ Investigaciones Bibliotecológicas de la \\ UNAM. Torre II de Humanidades, piso 12, \\ Ciudad Universitaria, México D.F. tel: 623 \\ 0343 \\ E-mail:marr@servidor.unam.mx
}

\section{RESUMEN}

$\boldsymbol{E}_{\mathrm{n}}$ el presente trabajo se busca la fundamentación ontológica de la Bibliotecología dentro de los marcos de la filosofía de Hiedegger, de Hegel, de Marx y de Husserl, llegando a la conclusión de la objetividad de la disciplina, la importancia que ésta tiene en el proyecto de existencia del hombre y el papel que desempeña para evitar la enajenación de la Humanidad como ser genérico.

\section{ABSTRACT}

In this paper it is searched the Library Science ontological basis, within the Hiedegger, Hegel, Marx, and Husserl philosophical frameworks. The conclussions reached are the discipline's objetivity, its importance in the man's existence proyect and the roll it carries out for preventing the humanity alienation as a generic being.

\section{FUNDAMENTACIÓN FILOSÓFICA}

$A^{1}$ analizar una disciplina desde el punto de vista filosófico se presenta en primer plano el problema del status ontológico de su objeto de estudio, de sus conceptos, enunciados, leyes y estructuras. Según U. Moulines el análisis y clarificación de ese status ontológico corresponde, en primer término, al científico que trabaja y desarrolla esa disciplina, pero que por motivos prácticos no lo hace, ya que se dedica esencialmente a la investigación propia de su área, "por ello es legítimo y hasta fructífero que el filósofo de la ciencia se ocupe de analizar los compromisos ontológicos que en principio el científico hace o debería hacer."1 Los elementos componentes de la disciplina deben ser objetivos, en el sentido de que versan sobre una parte de la realidad y las leyes de la teoría expresan unas relaciones entre objetos, dadas independientemente de la voluntad del sujeto.

Para nuestro análisis es importante no confundir la relación de los contrarios subjetivo-objetivo con la de ideal-objeti- vo. La primera expresa un par de categorías contradictorias de sujeto y objeto dentro del esquema del conocimiento que se excluyen mutuamente; podemos decir que una visión subjetiva ocurre cuando el objeto se pierde en el sujeto cognoscente y lo contrario, lo objetivo, se da cuando el objeto es opuesto claramente al sujeto, está frente al sujeto y se da como es (lo que no implica que se dé totalmente en toda su complejidad), además de que puede ser captado como tal no sólo por el sujeto que conoce, sino por todo sujeto potencial de la comunidad epistémica, lo que L. Villoro llama intersubjetividad.

Por otro lado, lo ideal y lo objetivo no son categorías contrarias, no se excluyen la una a la otra, sino que cada una de ellas expresa una relación diferente; la primera, una relación genética y la segunda, como ya se indicó, una forma de existencia opuesta al sujeto; algo ideal, genéticamente dependiente del sujeto y por consecuencia podría decirse subjetivo, puede ser objetivo en cuanto que en última instancia depende de la realidad y puede llevar una existencia independiente del sujeto, funcionalmente actúa opuesto al sujeto y en esa instancia puede ser investigado por este último, el cual tiene que descubrir las relaciones y funciones de los entes ideales, baste con recordar los números en las Matemáticas o los objetos de la Lógica, que son entes ideales, pero que tienen una existencia objetiva.

Después de esta breve aclaración, observamos que si utilizamos el método fenomenológico para el estudio del objeto de la Bibliotecología, encontramos, desechando todos los conocimientos anteriores, todos los "prejuicios", con palabras de Husserl, encerrando en un paréntesis todo juicio sobre esta disciplina, que la Bibliotecología trata de seres humanos, de bibliotecas, de documentos, de información y conocimientos que buscan esos seres humanos en esos documentos y de actividades de las bibliotecas para que 
esos seres humanos obtengan esa información y conocimiento que requieren, creando ellas mismas ciertos conocimientos y otros documentos.

En la fundamentación gnoseológica y posteriormente en la teórica se deberán analizar y describir estos elementos y sus relaciones, ${ }^{2}$ lo que nos importa en este momento es el hecho de que con base en su simple presencia podemos llegar a la conclusión - ya que el hombre es un ser social, la biblioteca es una institución social, el documento y el conocimiento tienen un carácter social-, de que la $\mathrm{Bi}$ bliotecología pertenece al campo de las Ciencias Sociales, cuestión que ya O. S. Chubarian destacó, colocando la Bibliotecología como una ciencia que estudia una de las formas de comunicación social masiva. ${ }^{3}$

La objetividad y la existencia de leyes en las Ciencias Sociales, así como el método propio de ellas han sido objeto de largas disputas entre diferentes corrientes filosóficas, las cuales se han acentuado principalmente en el siglo pasado y en el presente. Podemos recordar la posición del positivismo o del materialismo dialéctico que, cada uno empleando sus métodos característicos, afirman la posibilidad y necesidad de esa objetividad; o la posición de las escuelas neokantianas (Rickert), de Dilthey o la corriente de la Hermenéutica contemporánea, pasando por el anarquismo metodológico, que diferencian claramente los campos del conocimiento humano y le asignan a cada uno de ellos ciertas características específicas, incluyendo su propio método.

Esta situación de criticismo ante la objetividad de la disciplina se agudiza más aún si ésta, como es el caso de la Bibliotecología, responde a fines prácticos y su cuerpo teórico depende de la utilidad que puede tener para resolverlos, quedando el camino abierto para el arbitrio del suje- to, ya que existen varias opciones para alcanzar el fin deseado y si el sujeto escoge una de ellas es porque "le parece" la más adecuada, aunque podría haberse decidido por otra.

Para tratar esta problemática consideramos necesario partir de una premisa ontológica que podemos resumir con el término de realismo (la prioridad del ser de una realidad externa e independiente del sujeto) y una premisa gnoseológica que reconozca la capacidad del sujeto para conocer esa realidad.

De esa premisa ontológica se desprende el concepto de verdad que utilizaremos, consistente en el concepto clásico que dio Aristóteles, el cual expresa que la verdad es la adecuación del enunciado con la realidad: "Decir que el Ser no es o el no-Ser es, es falso; decir que el Ser es y el no-Ser no es, es verdadero."4

Por otra parte, es conveniente agregar a esas premisas una visión dialéctica de la realidad, consistente, no sólo en que todo está en movimiento y cambio, como comúnmente se cree, sino que todo está interrelacionado y cada elemento o momento es a un mismo tiempo absoluto y relativo, no se absolutiza ni lo relativo (no se cae en el relativismo), ni lo absoluto (tampoco se llega al dogmatismo); lo relativo tiene su elemento de absoluto y lo absoluto de relativo, todo en relación con el marco teórico, a la tarea que se analiza, al contexto en donde se encuentra.

De esta manera, podemos evitar caer en el dogmatismo metodológico (positivismo), en el anarquismo metodológico y finalmente esto nos ayuda a no caer en una dicotomía absoluta entre las ciencias naturales y las ciencias del espíritu, cada una tiene su lugar, sus características (eso lo hace absolutas), pero a la vez tienen puntos de contacto, influencia recíproca (eso las hace relativas).
De acuerdo con la visión fenomenológica del objeto de la Bibliotecología, podemos decir que este último es algo existente, independientemente del sujeto en el mundo real. Ese objeto está dado en la interrelación de Documento-Biblioteca-Usuario, en la búsqueda de este último para satisfacer sus necesidades de información, cognoscitivas y estéticas, pudiendo añadir necesidades sociales, económicas y políticas. El documento, con la salvedad de que en otra ocasión se dará una definición más estricta, se toma como un producto social y cultural, que es el resultado de la objetivación del espíritu humano. ${ }^{5}$ La biblioteca es el "espacio" que propone las condiciones necesarias para la satisfacción de las necesidades mencionadas del lector y el "lugar" donde no sólo se conserva la producción intelectual impresa de la humanidad, sino donde se puede dar y se da el autoconocimiento del espíritu humano objetivizado y permite su desarrollo. ${ }^{6} \mathrm{El}$ usuario es el ser humano (ideal) que por su estructura ontológica exige o puede exigir satisfacer ciertas necesidades que emanan de su ser específico.

La objetividad de la relación entre estos elementos está determinada por la misma existencia objetiva de ellos (quizá algunos de ellos son ideales como la información), además de que son las necesidades del ser humano la fuente de toda actividad bibliotecaria y esas necesidades emanan, como se expresó en el párrafo anterior, de su estructura ontológica; no son inventadas o creadas artificialmente, cuando más educadas o sofisticadas para ser satisfechas de determinada manera.

\section{EL HOMBRE COMO PODER SER Y LA BIBLIOTECOLOGÍA}

La afirmación de que la actividad bibliotecaria tiene su origen en las necesidades del ser humano encuentra su fundamento

2 De acuerdo con nuestra propuesta para la fundamentación de la Bibliotecología. Miguel Ángel Rendón Rojas. "Las tareas para la fundamentación de la Bibliotecología”. En Investigación bibliotecológica.Vol. 8, N. 17, jul.-dic. 1994. pp. 4-9.

3 O.S. Chubarian. Bibliotecología general. La Habana: Editorial Científico-Técnica, 1976. p. 9.

4 Aristóteles. Metafísica, 1011 b.

5 Esto se podría interpretar dentro de una concepción hegeliana, pero sin olvidar la premisa ontológica de la que partimos. Si se objetiviza el espíritu, no se trata de un espíritu Absoluto, independiente, individual y existente en sí anteriormente, sino de un espíritu colectivo (la Humanidad estrictamente como sujeto independiente no existe, pero existe a través de los seres individuales) y que se conoce a sí mismo al reflexionar sobre sus obras, al hacer metaciencia o filosofía de sus creaciones.

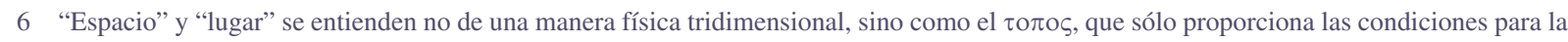
desobjetivización del espíritu humano. De esta manera, podemos desprendernos del nexo biblioteca-edificio, para dar cabida a otro tipo de bibliotecas: ambulantes, móviles, electrónicas, etcétera, e incluso, virtuales, si es que ellas realmente pueden proporcionar las condiciones mencionadas. 

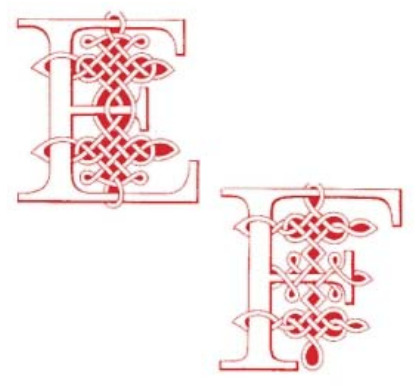
"El ser del hombre está referido a
la posibilidad no en un monólogo abstracto consigo mismo, sino inmerso en un mundo concreto de cosas y otras personas, es por esto que el ser del hombre es un Ser-en-el-mundo."

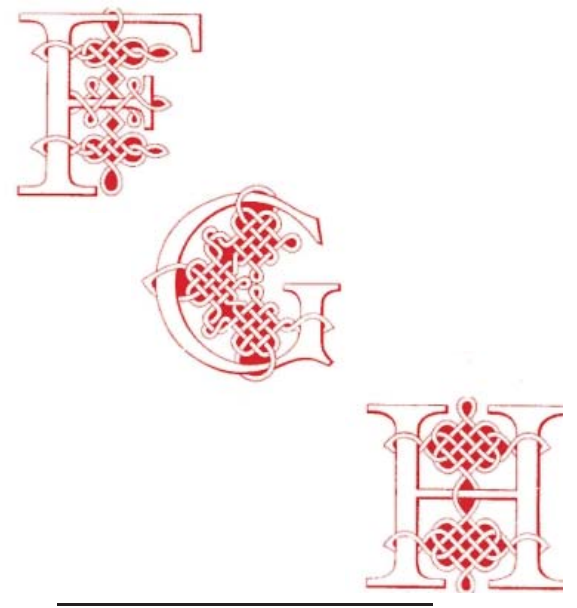

en el análisis fenomenológico que hizo Heidegger del ser del hombre. Como se recordará, Heidegger expresa que el ser del hombre se caracteriza, no por lo que es, sino porque siempre está en proceso de ser, siempre se halla frente a un complejo de distintas posibilidades, las cuales no todas necesariamente se realizan. El hombre siempre está referido a su ser como a su posibilidad, se descubre al hombre como "poder ser". El poder ser es el sentido mismo del concepto de existencia y la esencia del hombre es la existencia.

El ser del hombre está referido a la posibilidad no en un monólogo abstracto consigo mismo, sino inmerso en un mundo concreto de cosas y otras personas, es por esto que el ser del hombre es un Ser-en-el-mundo. El hombre como existencia hace su proyecto dentro de ese mundo, encuadrando las "cosas" del mundo en su proyecto, por lo tanto, ellas tienen cierta significación, las cosas antes de ser simples presencias son instrumentos y su utilidad o su significado en relación con nuestra vida es su modo más original de darse. Esto no quiere decir que las cosas sean todas medios que empleamos efectivamente, sino que se nos presentan, ante todo, provistas de significación.

Esta significación está dada en cuanto el instrumento está constituido en función de otro (el instrumento nunca está aislado, siempre es instrumento para algo, es usado por alguien en ciertas circunstancias, está hecho de algo) y por lo tanto posee el carácter de la denotación. Pero propiamente, el instrumento no es para denotar sino para usarse. Sin embargo, existe un objeto al cual la función denotativa es algo constitutivo, la utilidad concuerda con su capacidad denotativa, ese objeto es el signo, el cual se interpreta como las instrucciones para usar instrumentos.

Por otro lado, Ser-en-el-mundo no es sólo estar en medio de una totalidad de instrumentos, sino el estar familiarizados con una totalidad de significados. El hombre a través de una precomprensión, que es cierto "patrimonio de ideas", ciertos "prejuicios" que se tienen y del adecuado uso de los signos, llega a una comprensión que articula los significados. ${ }^{7}$
De esta semilla se desprende la concepción que el Heidegger tardío haría sobre el papel del lenguaje en la ontología. El lenguaje no es sólo el sistema de signos por antonomasia y que como tal nos proporciona el significado de las cosas (nos da las instrucciones para emplear los instrumentos), no sólo es el receptor en donde se transmite el patrimonio de ideas que permite la precomprensión, sino que el lenguaje es "la casa del ser" porque al nombrar al ente lo hace aparecer y donde no hay lenguaje no hay apertura del ente.

Para nuestros fines es suficiente constatar el hecho de que el hombre como proyecto que se realiza en un mundo de cosas, necesita una orientación para llevarlo a cabo, necesita unas instrucciones para desenvolverse en ese mundo, necesita del lenguaje para encontrarse con el ente y necesita del patrimonio de ideas que le permita tener una precomprensión para llegar a la comprensión; uno de los instrumentos, entre otros, que satisface estas necesidades, es la actividad bibliotecológica, de ahí su objetividad, su importancia y lugar privilegiado que debe poseer en su proyecto. Efectivamente, mediante esta actividad se le ofrecen al hombre unas instrucciones (información y con base en ésta puede crear conocimientos) para desenvolverse en el mundo, se le proporciona la tradición cultural impresa en documentos para que obtenga la precomprensión que lo llevará a la organización de sus conocimientos y por último si el lenguaje es la casa del Ser y la biblioteca es la casa de uno de los tipos de lenguaje, entonces la biblioteca guarda al Ser y además si recordamos la noción de verdad de Heidegger como develación del Ser, entonces en la biblioteca está el Ser que tiende al hombre para revelarse a él.

Al mismo tiempo, si recordamos los conceptos de Heidegger de "existencia auténtica" y "existencia inauténtica" también podemos llegar a fundamentar la objetividad e importancia de la Bibliotecología. El hombre en el mundo se puede realizar de una manera irreflexiva y acrítica en un cierto contexto histórico-social, en sus prejuicios y en el modo "común” de ver y juzgar las cosas, vive en la cotidianidad y se esconde en la generalidad, en el anonimato del "se", piensa lo 
que se piensa, usa lo que se usa y actúa como se actúa; esta forma de existir es llamada por Heidegger como inauténtica. Pero si esas opiniones generales las elige para adoptarlas conscientemente en su proyecto, se apropia de las cosas mismas, que son instrumentos y significados y la interpretación surge de ellas para él, la existencia es auténtica. La biblioteca le proporciona la oportunidad al hombre para llegar a una existencia auténtica a través del lenguaje, el lenguaje le descubre el ente y así la posibilidad de apropiarse de él e incluirlo en su proyecto.

Por otro lado, parecería que dos pensadores tan disímiles como Marx y Heidegger no pueden coincidir en un solo punto, pero si disminuimos el grado de abstracción, dejando de hablar de una ontología pura, para pasar a algo más concreto, encontramos que Marx expresó la idea de que los hombres antes que hacer historia, ciencia u otra actividad espiritual, necesitaban vivir. Pero para vivir es necesario poseer cierta información que nos permita orientarnos en este mundo y actuar de una manera congruente con la realidad, y ciertos conocimientos (desarrollados a lo largo del proceso histórico de la humanidad), los cuales proporcionan las posibilidades no para adaptarse al medio pasivamente, sino para transformarlo, característica propia de la especie humana; y según nuestro enfoque, esa información y conocimientos se obtienen, entre otras cosas, con la ayuda de la actividad bibliotecaria. Por lo que una vez más encontramos la fundamentación objetiva de esa actividad, no es la ciencia la que determina el Ser, sino el Ser lo que determina la existencia de la disciplina.

\section{LA ENAJENACIÓN Y LA BIBLIO- TECOLOGÍA}

Por otro lado, si continuamos con el análisis del pensamiento de Marx, pero el Marx filósofo de los manuscritos de 1844, llegamos a otra fundamentación ontológica de la Bibliotecología mediante el concepto de enajenación. Si ante-

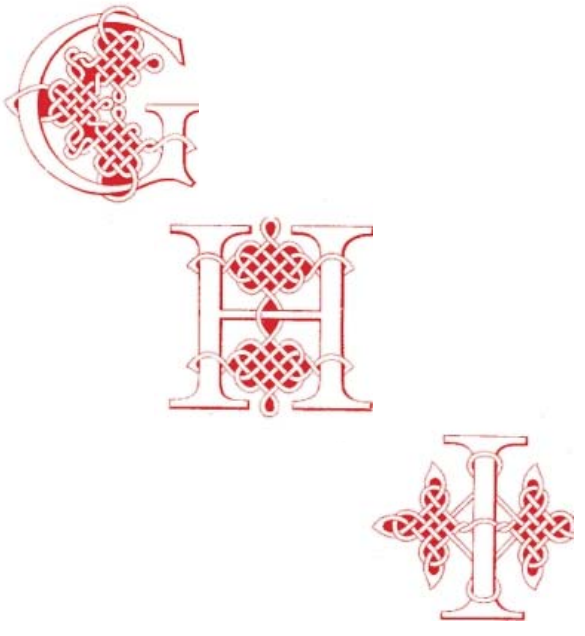

\section{“La biblioteca le proporciona la oportunidad al hombre para llegar a una existencia auténtica a través del lenguaje, el lenguaje le descubre el ente y así la posibilidad de apropiarse de él e incluirlo en su proyecto."}
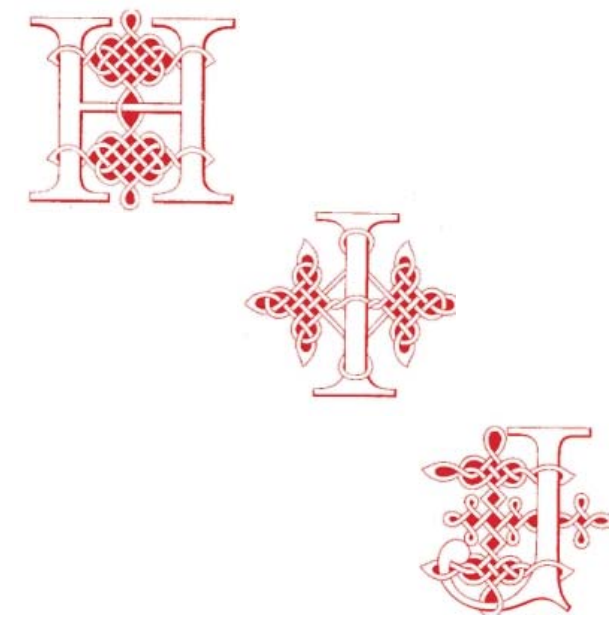

riormente se habló de la "utilidad práctica", si se nos permite utilizar esa expresión, ahora se hablará de una "utilidad cognoscitiva".

Al analizar el proceso de producción, Marx descubre que el hombre objetiviza su esencia en el producto de su trabajo, es decir, cada cosa hecha por el hombre posee parte del hombre mismo. En este fenómeno no existe nada anormal, una esencia objetivada no es aún una enajenación, ésta comienza cuando se pierde el control sobre la esencia propia objetivada, debido a que el producto del trabajo (que es o tiene parte de la esencia de su productor) no pertenece a su creador, no es de él. ${ }^{8}$

El trabajo objetivado, el producto, pertenece a otro que se apropia de él y de esta manera el producto se enfrenta a su creador. Marx llegó a la conclusión de que para que no haya enajenación, el productor debe ser el dueño de su producto y propone "la real apropiación de la esencia humana por y para el hombre; [...] el retorno del hombre para sí [...] el retorno pleno, consciente [de la propia esencia], logrado dentro de toda la riqueza de la evolución anterior [...] como humanismo acabado."9

Si nosotros, siguiendo el hilo de ese razonamiento, descubrimos que la Humanidad como sujeto ideal (ser genérico, ser universal) ha sido el creador de obras plasmadas en documentos, entonces para que no haya enajenación, cada hombre, como parte de esa Humanidad debe "apropiarse" de ellas, por supuesto que no materialmente, sino espiritualmente, idealmente, puesto que estamos hablando de creaciones espirituales. La esencia de la Humanidad plasmada en esas obras debe llegar a personas individuales que al conocerlas se apropien de esa esencia y entonces no sólo no hay enajenación, sino autoconocimiento del espíritu humano. De aquí los conceptos de documento como objetivación del espíritu humano y de la biblioteca como uno de los lugares donde no sólo se da informa-

8 "El producto del trabajo es el trabajo que se ha plasmado en un objeto, el objeto es la objetivación del trabajo [...] la objetivación [se manifiesta] como la pérdida [...] como enajenación.

“[...] La enajenacióndel obrero en su producto significa no sólo que su trabajo se ha transformado en un objeto, en una existencia externa, sino que esta existencia está fuera de él, es independiente de él y ajena a él y representa un poder propio y sustantivo frente a él [...] se enfrenta a él como algo extraño y hostil.” K. Marx. y F. Engels. Manuscritos económico-filosóficos de 1844. Bogotá: Editorial Pluma, 1980. p. 69.

9 K. Marx. Op. cit. p. 105.

Dejemos, por el momento, a un lado la solución político-económica de fondo (abolición de la propiedad privada sobre los medios de producción) que propone Marx y quedémonos con la visión filosófica de enajenación que viene desde Hegel. (No por desechar la postura política perdamos la semilla filosófica que puede dar muchos frutos). 
ción y conocimientos, sino en donde se realiza el autoconocimiento del espíritu humano objetivizado.

Ahora bien, es claro que no se afirma la necesidad de que cada ser humano tenga conocimiento de todas las creaciones que a lo largo de su historia la Humanidad ha creado, cosa por supuesto imposible de realizar, dada la limitación de tiempo, recursos y capacidad de asimilación de cada hombre particular y la magnitud de obras creadas, además de que últimamente, conforme pasa el tiempo, se acelera su producción; sino que únicamente se expresa el hecho de que potencialmente se dé esa posibilidad de conocimiento, que se va a actualizar de acuerdo con las necesidades del lector, no es indispensable que un sociólogo, por ejemplo, tenga que conocer lo que se ha escrito sobre Física Teórica, pero si en un determinado momento surge la necesidad de hacerlo, lo pueda hacer; cosa que no era posible con un libro de Trotsky en la Rusia soviética después de los años treinta, o con trabajos de instituciones militares.

Por otro lado, Marx habla también de que si existe el producto enajenado y si el producto no es otra cosa que el resumen de la actividad, de la producción, entonces la producción misma, el proceso por el cual se creó ese producto ha de ser necesariamente un proceso enajenado. ${ }^{10}$

Ahora bien, si analizamos este fenómeno en el campo de la cultura y particularmente en el de la Bibliotecología, podemos observar cómo la biblioteca y la actividad bibliotecaria en general son importantes no sólo para los posibles usuarios, sino para el autor (literato o científico) de los documentos.

El autor, al crear su producción documental (literaria o científica), actúa como ser individual y ser genérico, y de acuerdo con el concepto de enajenación analizado, en el primer aspecto su obra debe pertenecer a él mismo y en el segundo, a la Humanidad en general, de lo contrario la actividad por la que creó esas obras es una actividad enajenada. Ahora bien, en ambos casos el autor produce en función de un lector, escribe para ser leído (de ahí que se diga que la ciencia es comunicable en esencia); por lo que podemos decir que el modelo ideal consiste en que el autor escribe para el lector y este último lee esas obras, sin otros condicionantes más que su necesidad de información. Pero la forma en que se realiza la apropiación de la obra en esos diversos planos no es igual e incluso puede presentarse una contradicción entre ellas.

En el plano individual, el autor persigue ser dueño de su obra, así como de los beneficios que de ella puede obtener, la obra debe pertenecer al autor (de ahí los derechos de autor que se reconocen en el mundo contemporáneo), debe crear libremente sin presiones, podemos recordar a Dostoievsky quien escribió siempre bajo la presión económica y de los editores, o al conde León Nikolaievitch Tolstoi que no tuvo tales. Precisamente por estar inmersos en una sociedad mercantilista, en donde, según expresión de Marx, rige un fetichismo, el autor puede preferir trabajar donde haya más retribución económica aunque menos lectores (los trabajos de investigación realizados por instituciones elitistas). Pero por otro lado, en el plano general, sin el lector, el hombre como género está sin realizarse, la producción espiritual es una actividad enajenada y no por esto el autor va a renunciar a sus derechos para que se editen sus obras gratuitamente en bien de la Humanidad. 11

Es aquí donde la biblioteca, aun en esta sociedad mercantilista, puede conciliar esta contradicción, respetando los derechos de autor, reconociendo que existen otras instituciones privadas que cobran sus servicios, ${ }^{12}$ pone al alcance de los que así lo deseen (según el tipo de biblioteca de que se trate) los documentos para que éstos tengan lectores. Por lo tanto, si el autor escribe para ser leído, escribe para el lector; la biblioteca proporciona lectores al autor, por lo que este último no depende de la coyuntura económica, y de esta manera el autor individuo y el autor genérico tienen sus lectores.

De esta manera, podemos constatar la diferencia entre una bodega, una tienda de libros y la biblioteca. El lugar donde realmente encuentra su ser el documento es en esta última institución, donde puede ser apropiado por los lectores, en la primera sólo es un lugar donde se le almacena sin esperanzas de ser consultado, en la segunda aparece no en su ser auténtico, sino como mercancía y fue creado no para ser intercambiado por otra mercancía (el dinero) sino para ser leído. Es interesante apuntar que con otro enfoque, el planteamiento de E. Cassirer y E. Nicol, S. Sander llegó a una conclusión semejante: el libro no es para ser "usado sino leído". 13

\section{DISCIPLINAS PRÁCTICAS Y TEÓRICAS}

Por último, trataremos la cuestión del carácter pragmático de la Bibliotecología. Se ha criticado a la Biliotecología por ser una disciplina eminentemente práctica, en donde sus reglas están en función de alcanzar unos fines pragmáticos concretos y no se ve claramente su estructura teórica. Se recuerda la concepción de Aristóteles, quien afirmaba que la ciencia tiene por objeto obtener un conocimiento desinteresado, el único interés que la guía es el afán de conocer por conocer, y por lo tanto, si no se cumple este requisito de contemplación teórica desinteresada, se le niega el carácter científico a la Bibliotecología.

Sin embargo, Marx descubre que esa posición no es la adecuada, puesto que todo se realiza para un fin, toda actividad, incluida la teórica, se efectúa movida por un interés: el de satisfacer necesidades reales; las necesidades son el principio motor de toda actividad, incluso la filosófica, ya que la Filosofía — conocimiento contemplativo por excelencia para Aristóteles - surge como respuesta a una necesidad, la de responder a la pregunta de cuál es la relación entre el YO y el No-YO, la Filosofía pretende dar una

10 K. Marx. Op. cit. p 70-71.

11 Eso es un problema económico-social, los bibliotecarios no lo van a resolver por completo, mientras exista la sociedad capitalista donde las relaciones son mediatizadas por la mercancía (el dinero), ese problema estará presente.

12 Es interesante constatar que en otras áreas no menos importantes para el desarrollo del Ser del hombre como la educación y la medicina, coexisten pacíficamente instituciones privadas y públicas, existe la posibilidad de elección a dónde dirigirse para satisfacer las necesidades educativas o de salud, lo importante es que estén al alcance de todos.

13 S. Sander. “Qué es la bibloteca?” En Edición conmemorativa del X aniversario del Centro Universitario de Investigaciones Bibliotecológicas CUIB, 1992. p. 40. 
cosmovisión racional que permita orientarnos en el Cosmos cuando los mitos no son suficientes para responder a esa cuestión.

Por otro lado, ya Husserl expresó y demostró la idea de que toda disciplina práctica descansa en un cuerpo teórico, en cuanto que sus reglas han de poseer un contenido teórico, separable de la idea del deber ser.

Expliquemos brevemente el razonamiento de Husserl y sus implicaciones concretas para la Bibliotecología. Las reglas de la disciplina práctica expresan lo que debe ser, señalan una exigencia por realizar cierta actividad de determinada manera y con ciertas condiciones. Podemos recordar las reglas de clasificación como elementos integrantes del conocimiento bibliotecológico, que precisamente nos indican cómo realizar una actividad.

Las reglas de la disciplina práctica incluyen en sí un juicio valorativo, en cuanto que si se respeta esa exigencia se alcanza un fin que se considera positivo. Pero esta exigencia tiene razón de ser sólo en cuanto el juicio de valor es válido. Por lo tanto, la expresión "un A debe ser un B" es equivalente a "sólo un A que es B es un buen A" o "un A que no es B es un mal A". El concepto de "bueno" (valioso) o "malo" (no valioso) se aplica a cierta clase de objetos, los cuales se dividen en buenos y malos con base en ese concepto. Para poder pronunciar el juicio valorativo "un A debe ser B", necesitamos tener el concepto de "buen B"; y este concepto no puede radicar en una arbitraria definición nominal, sino en una relación, tal como se puso de manifiesto en el análisis ontológico arriba expuesto, "un B es bueno en cuanto satisface necesidades reales emanadas de la estructura ontológica de un D", si no las satisface, entonces no es un buen B; y las satisface porque corresponde a características reales de objetos o relación entre objetos. Así, la regla que expresa que en la industria alimentaria cierto producto debe ser preparado a una determinada temperatura, durante un tiempo preciso, etcétera, es porque el cumplimiento de esa regla satisface idóneamente la necesidad del hombre de alimentarse: las cadenas proteínicas, las vitaminas y otras sustancias no se destruyen y pueden ser asimiladas; de lo contrario, si la temperatura o el tiempo de preparación es mayor o menor de lo prescrito por la regla, entonces no se logra el objetivo deseado; el alimento pierde sus propiedades alimenticias o permanece crudo. Esto es porque la regla refleja las características y relaciones objetivas entre "objetos", tales como temperatura, tiempo de cocimiento y estabilidad estructural (química) de vitaminas, proteínas, etcétera. En Bibliotecología ocurre lo mismo, ciertas reglas se utilizan porque cumplen con la finalidad de satisfacer las necesidades del lector, enumeradas anteriormente desde una perspectiva de Heidegger, Hegel y Marx; además las cumple porque refleja relaciones objetivas entre objetos como son las características del documento y su simbolización, la consistencia y completud del sistema de símbolos y otros.

Como se puede observar, dentro de los enunciados normativos existe uno que exige en general a los objetos de ese campo que satisfagan en la mayor medida posible a las notas constitutivas del predicado positivo de valor. Esta proposición normativa ocupa un lugar privilegiado dentro del sistema de juicios normativos y se le puede llamar norma fundamental, es decir, respecto a ella debe verificarse toda valoración que se realice dentro de la disciplina práctica.

De esta manera, cada uno de los enunciados normativos tiene la idea común de la conmensurabilidad con la norma fundamental, pero además posee un contenido teorético propio, que permite distinguir unos de otros. La relación de conmensurabilidad entre la norma y lo sometido a la norma se caracteriza objetivamente como una relación entre condición y condicionado, relación que se presenta existente o no existente en la proposición normativa correspondiente. Así, toda proposición del tipo "un A debe ser B" implica la proposición "sólo un A que es B tiene las cualidades C". La nueva proposición es puramente teórica y tiene su lugar en un cuerpo teórico (propio de esa disciplina o importada de otras); por lo tanto, si la ciencia práctica ha de merecer ese nombre, es necesario que se investiguen científicamente las relaciones entre las relaciones objetivas que se tratan de someter a las normas y a la norma fundamental, y para esto es indispensable que se estudie el fondo teorético de estas relaciones, entrando así en el campo de
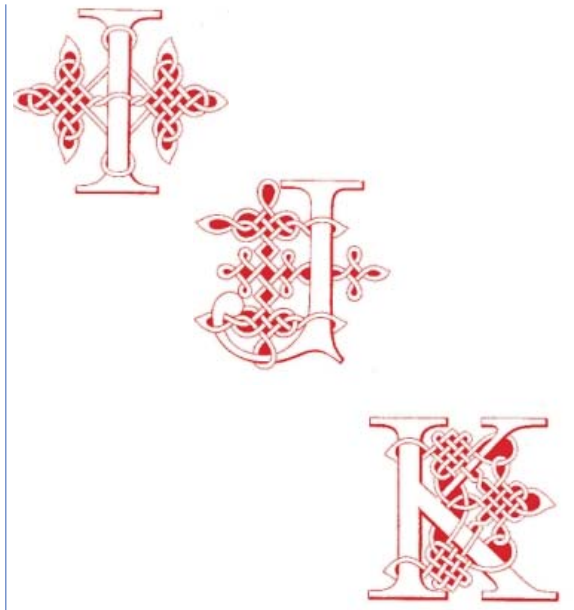

“ La Bibliotecología no es el producto de una invención arbitraria de una comunidad, sino que nace de necesidades reales y en su cuerpo teórico refleja relaciones objetivas entre elementos también objetivos, y su futuro desarrollo estará determinado por satisfacer esas necesidades, adecuándose al desarrollo de esos elementos y sus relaciones."
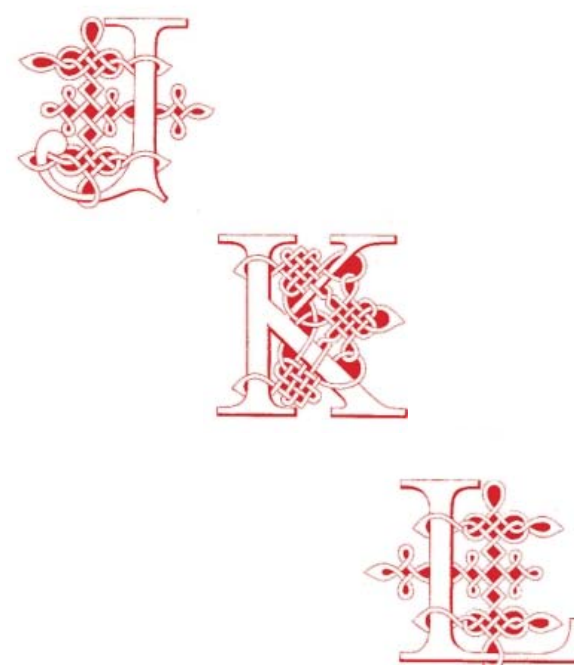
las ciencias teóricas. ${ }^{14}$ De esta manera se pasa, según nuestro planteamiento, a la fundamentación teórica de la disciplina.

\section{CONCLUSIÓN}

Según se pudo observar en el desarrollo de esta exposición, la Bibliotecología no es el producto de una invención arbitraria de una comunidad, sino que nace de necesidades reales y en su cuerpo teórico refleja relaciones objetivas entre elementos también objetivos, y su futuro desarrollo estará determinado por satisfacer esas necesidades, adecuándose al desarrollo de esos elementos y sus relaciones.

Es interesante e importante hacer una reflexión sobre las llamadas leyes bibliotecológicas de Ranganathan y analizarlas a la luz del planteamiento aquí expuesto. ${ }^{15}$ Esas leyes son más bien principios que rigen una actividad, son normas, que permiten lograr una finalidad (recuérdese a Husserl), pero esos principios tienen como fundamento unos elementos obje- tivos reales (recuérdese a Hegel y a Marx).

$\mathrm{Si}$ "los libros son para usarse", "los libros son para todos", "cada libro tiene su lector" y "se debe ahorrar tiempo a los lectores" es porque los libros deben ser parte integrante del proyecto existencial del hombre, ellos permiten el autoconocimiento del espíritu humano objetivizado y su ausencia en la vida del hombre conlleva a una existencia inauténtica, a una falta de comprensión de la existencia (naturaleza, hombre y sociedad), a una enajenación de la Humanidad. Si "la biblioteca es un organismo en constante desarrollo" es porque está ligada al ser del hombre que no es más que "un poder ser", es decir, un ser en desarrollo y esa relación determina la dialéctica consecutiva de la biblioteca con el Hombre.

De esta manera, podemos concluir que, tal como nos lo advirtió Moulines, los miembros de la comunidad científica que trabajan en la investigación de su área poseen implícitos determinados compro- misos filosóficos que deben ser puestos en evidencia mediante un análisis metacientífico de esa disciplina. Esto no significa que podamos aseverar unívocamente que Ranganathan se basó en ese marco filosófico o que estaría de acuerdo con él, tal vez tenía presente una filosofía oriental u otra, pero lo que sí podemos afirmar es que si aceptamos ese marco propuesto por nosotros, que a su vez está debidamente fundamentado, entonces esto nos ayudará a comprender más profundamente la disciplina de la Bibliotecología. Tal vez alguien proponga otro marco filosófico, pero en ese caso, tendría que fundamentarlo y con base en él fundamentar la Bibliotecología. Lo atractivo de nuestra propuesta radica en que se basa en la tradición filosófica occidental, comprensible para nosotros, respeta el realismo, considera la verdad como correspondencia, alejándose de convencionalismos y pragmatismos, y no se cae en relativismos, dogmatismos e irracionalismos.

\section{BIBLIOGRAFÍA}

Chubarian, O. S. Bibliotecología general. La Habana: Editorial Científico Técnica, 1976.

Gorbea Portal, S. y E. Setién Quesada. "De la Bibliiotecología al Sistema de Conocimientos científicos Bibliotecológico-Informativo”. En Investigación Bibliotecológica. N. 16, 1994. p. 21-25.

Hegel, G. W. Enciclopedia de las ciencias filosóficas. México: Porrúa, 1985.

Heidegger, M. “Carta sobre el humanismo”. En Realidad, N. 7, Buenos Aires, 1948. p. 13-25 y N. 9 p. 343-367.

———. El Ser y el tiempo. México: FCE, 1980.

Husserl, E. Investigaciones lógicas, 1. Madrid: Alianza Editorial, 1985.

Marx, C. Manuscritos económico-filosóficos de 1844. Bogotá: Editorial Pluma, 1980.

Moulines, U. Exploraciones metacientíficas. Madrid: Alianza Editorial, 1982.

Ranganathan, S. R. The five laws of Library Science. Bangalore, India: Sarada Ranganathan Endowment for Library Science, 1989.

Rendón Rojas, Miguel Ángel. "Las tareas para la fundamentación de la bibliotecología”. En Investigación bibliotecológica. Vol. 8. N. 17. jul.-dic. 1994. pp. 4-9.

Sander, S. “¿Qué es la Biblioteca?” En Edición conmemorativa del X aniversario del Centro Universitario de Investigaciones Bibliotecológicas. México: Consejo Nacional para la Cultura y las Artes, Centro Universitario de Investigaciones Bibliotecológicas, 1992. p. 33-42.

Vattimo, G. Introducción a Heidegger. Barcelona: Editorial Gedisa, S. A., 1986.

14 E. Husserl. Investigaciones lógicas, 1. Madrid: Alianza Editorial, 1985. p 60-65.

15 S.R. Ranganathan. The five laws of Library Science. Bangalore, India: Sarada Ranganathan Endowment for Library Science, 1989. 